\title{
A SOCIEDADE DIGITAL É TERRA SEM LEI? O DIREITO AUTORAL NA ERA DA
} INTERNET.

\author{
Gilberto Batista Santos ${ }^{1}$
}

\section{RESUMO}

Com o advento as Sociedade da Informação, cada vez mais ganha espaço no campo jurídico o debate sobre a forma como vamos proteger esses direitos autorais em uma sociedade cada dia mais conectada, até hoje ainda somos preenchidos por interrogações no que concerne a questões sobre as políticas de privacidade dos conteúdos publicados na internet e os meios de utilização destes conteúdos sem que cometamos atos ilícitos. Nesse interim, esse estudo tem como objetivo analisar a utilização dos conteúdos da internet para melhor alinhar e manter o equilíbrio entre o direito autoral e o direito à informação. Para tanto, aplica-se à pesquisa o método dedutivo e o método de Abordagem Baseada em Direitos (Right Based Aprooach RBA), método vinculado ao Grupo de Pesquisa Propriedade Intelectual da Universidade do Estado da Bahia (UNEB).

Palavras-Chave: Direito Autoral; Internet; Lei no 9.610/98; Sociedade da informação;

\section{IS THE DIGITAL SOCIETY EARTH WITHOUT LAW? COPYRIGHT IN THE ERA OF THE INTERNET.}

\begin{abstract}
With the advent of the Information Society, the debate on how we are going to protect these copyrights in an increasingly connected society is increasingly gaining ground in the legal field, even today we are still filled with questions regarding policy issues. privacy of content published on the internet and the means of using this content without committing illegal acts. In the meantime, this study aims to analyze the use of Internet content to better align and maintain the balance between copyright and the right to information. To this end, the deductive method and the Right Based Approach (RBA) method are applied to the research, a method linked to the Intellectual Property Research Group of the State University of Bahia (UNEB).
\end{abstract}

Key words: Copyright Law; Internet; Law N. 9,610/98; Information society;

\section{INTRODUÇÃO}

Com o avanço da tecnologia e da informática e das Redes Sociais, o mundo contemporâneo está passando por uma transição sem precedentes na história. Atualmente, as informações chegam às pessoas em tempo real e se difundem numa velocidade inimaginável

\footnotetext{
${ }^{1}$ Professor universitário, graduado em Direito, mestre em Gestão de tecnologia, graduando em História. Pesquisador Grupo de Pesquisa Propriedade Intelectual da Universidade do Estado da Bahia (UNEB). Advogado do CRDH/UNEB. E-mail: advgilbertobatista@gmail.com.
} 
até poucos anos atrás. Após diversas transformações determinadas por uma revolução digital, cresce cada vez mais uma economia voltada para o mundo digital, constituindo um caminho sem volta.

A revolução digital fortaleceu as tendências da globalização moderna, diminuindo as fronteiras geográficas, intensificou a confiança no on-line. Entretanto, ao mesmo tempo o acesso a internet vem registrando um grande aumento de usuários, resultado do crescente número de computadores, da inclusão digital e, sobretudo, da maior credibilidade dos usuários a essa interação social, essa popularidade tem por outro lado acarretado um crescente número de violações aos direitos autorais.

Nesse diapasão, o acelerado desenvolvimento tecnológico e o advento da internet também contribuem significativamente para impulsionar a violação aos direitos autorais. Assim, o Direito como instrumento regulador das condutas sociais não poderia se calar diante de tantas transformações, no que tange as questões que giram em torno da violação dos Direitos Autorais no mundo cibernético.

É importante destacar, que a pesquisa não pretende indicar a internet ou as Redes Sociais são as causas da violação desses direitos, muito menos deseja criar obstáculos para a utilização de obras intelectuais nesses ambientes, fato este que poderia criar uma espécie de Estado de Exceção Virtual ${ }^{2}$.

Esse trabalho é fruto dos debates dentro do Centro de Referência em Desenvolvimento e Humanidades - $\mathrm{CRDH}^{3}$, em que ao ter contato com as demandas dos grupos atendidos no Centro, passamos a verificar que diversos conteúdos eram retirados das Redes Sociais, por violação a política de propriedade intelectual.

Nesse sentido, diante da realidade em que nossa vida passou a ser "navegável", desde eventos simples do cotidiano como a publicação de uma foto ou a gravação de um vídeo, criando uma convergência entre o mundo físico e o digital com a interconectividade entre

\footnotetext{
2 A pesquisa adota como fundamento a teoria do estado de exceção de Giorgio Agamben (2018), para estabelecer quando o Estado cria obstáculos ou regras que inviabilizam a participação social no ambiente virtual, podemos estar diante de um Estado de Exceção Virtual. O próprio Agamben estabelece que o estado de exceção não deve ser visto exclusivamente como uma medida provisória, mas deve ser analisado como um paradigma estabelecido pelo governo, nesse sentido, é importante estabelecer que a ideia do Estado de Exceção Virtual não se trata de uma quimera, notadamente quando Agamben constitui que a política moderna vem se adaptando cada vez mais para estabelecer um estado de exceção permanente.

${ }^{3}$ Órgão suplementar da UNEB que conta com uma plataforma com cinco laboratórios de pesquisa aplicada em ciências humanas, sociais e sociais aplicadas: Observatório da Educação (Obedhuc), a Incubadora Tecnológica de Economia Criativa (CriaAtiva), e a Rede de Educação em Direitos Humanos (Mbote), o Laboratório de Imagem, Memória e Documentação (Lindo) e o Laboratório de Áudio, Sonorização e Iluminação profissional (Lasio).
} 
pessoas e aparelhos (coisas), gerando a produção de direitos de propriedade, Diante disso, o presente artigo tem como objetivo analisar como a utilização dos conteúdos da internet podem violar os direitos do autor, para melhor alinhar e manter o equilíbrio entre o direito autoral e o direito à informação das mensagens que são disseminadas nas Redes Sociais e não visam lucro, embora, possam continuar a violar esses direitos, pois lidam basicamente com a imaterialidade característica da propriedade intelectual.

É importante enfatizar que cotidianamente a sociedade se vê afrontada por litígios e problemas ligados ao uso massificado da informática, em especial os Direitos Autorais e o grande desafio para o Direito são a compreensão e o acompanhamento das inovações geradas pela tecnologia, garantindo a pacificação social e o desenvolvimento de posturas éticas necessárias no momento da utilização dos conteúdos da internet.

Embora após décadas da implantação da Internet no Brasil, o país ainda vive grande insegurança jurídica na proteção aos direitos autorais conferidos por lei à pessoa física ou jurídica, autora da obra intelectual para resguardá-la, caso haja a utilização de suas criações. Vale ressaltar que o direito autoral recebe o amparo regulador da Lei 9.610/98 e refere-se as relações entre o autor e quem utiliza suas criações de forma inadequada.

A Lei n⿳⺈ 9.610/98 vigora com alterações no seu Art. $1^{\circ}$, que prevê o regulamento dos direitos de autor e os que lhes são conexos, assim como, o equilíbrio dos ditames constitucionais de proteção a tais direitos (BRASIL, 1998).

\section{DE GUTEMBERG À WIKIPÉDIA: A EVOLUÇÃO HISTÓRICA DOS DIREITOS AUTORAIS}

Antes de adentramos na utilização das obras protegidas por direitos autorais na "era da internet", por uma questão didática abordaremos uma breve evolução da proteção desses direitos. $\mathrm{Na}$ antiguidade, os direitos autorais eram conhecidos como direito do editor, nascido a partir de alguns benefícios concedidos pelo Estado/Igreja aos livreiros para que estes publicassem obras intelectuais em geral com fins econômicos, o direito autoral foi sofrendo grandes modificações devido ao seu crescimento e inevitáveis consequências econômicas Carvalheiro (2008, p.67) diz:

Na Antiguidade até o início da Idade Média, não havia a preocupação de estabelecer a responsabilidade pelo fechamento da obra, as histórias estavam em contínuo processo de criação, os contadores tinham o direito de decidir, segundo a sua própria vontade, o que acrescentar, melhorar ou modificar. As narrativas, tragédias, comédias, epopéias - textos, hoje denominados de literatura - eram postas em 
circulação e valorizadas sem que se colocasse em questão a autoria, já que o anonimato não constituía um empecilho, a sua própria antiguidade era uma garantia suficiente de autenticidade.

Seguindo essa linha evolutiva até a comunicação e utilização das obras protegidas por direitos autorais dentro do espaço da internet, é imperioso destacar, que antes de determos as capacidades de copiar uma obra em fração de segundo e disponibilizar no ciberespaço, na Roma antiga as obras eram transcritas manualmente e apenas os copiadores eram remunerados e pelos seus feitos. Os autores apenas recebiam honrarias pelas suas obras quando fiéis ao texto originário. Ainda que não existisse nenhuma lei sobre os direitos autorais, os infratores já eram punidos em danos patrimoniais, e no que toca aos direitos morais, eles eram desqualificados intelectualmente. De acordo com Barros (2007, p. 468):

Em Roma, com a figura dos copistas - profissionais remunerados que reproduziam as obras por meio de cópias manuscritas - o direito autoral ganhou uma primitiva forma jurídica, pois passava a obra [...] a ter duas conotações em termos de propriedade: a moral, de quem desenvolvia a atividade criadora em si, e a econômica, exclusiva daquele que se investia no mero trabalho de reproduzi-la.

Assim, os copistas eram pessoas competentes portadores de uma diversidade cultural que o capacitava para intervir de modo preciso nos escritos de cunho moral, religioso e social organizando os escritos. O direito do autor se consolidou com a Revolução Francesa em 1789, adicionando aos direitos individuais termo como copyright (direito de cópia), que reconhece formalmente a paternidade das obras não sendo possível a modificação delas sem o prévio conhecimento daqueles. Para Nigri (2006, p.15):

"[...] o sistema europeu passou a ser conhecido como direito de autor, tutelando o criador da obra, contrapondo-se e ao mesmo tempo convivendo com o sistema anglo americano do copyright, cuja tutela se assenta na materialidade da obra. Quanto aos direitos morais de autor, sua tutela independia do privilégio concedido.

Assim, o direito do autor, os direitos morais, patrimoniais e conexos passaram a ser vistos como importantes ferramentas para uma nova modalidade de sociedade que nascia ganhando espaço no desenvolvimento. Existem várias vertentes quanto a origem histórica de tais direitos, porém, possuem correntes que associam o surgimento do direito de autor ao advento da imprensa na Europa. Entretanto, somente após o Renascimento, que os direitos autorais foram inseridos nos sistemas legislativos ao redor do mundo (BARROS, 2007).

Diante disso percebe-se que o direito do autor foi consagrado pela civilização clássica, até mesmo antes da imprensa. Portanto, entende-se como direito do autor, a seção do direito privado que regulamenta as relações no campo jurídico de caráter pessoal e/ou patrimonial, 
produto da obra de inteligência e de sua utilização com intuito econômico. O Direito do Autor embora pertença a um ramo próprio do direito encontra-se dentro do Direito Civil, que surgiu para ofertar ao autor a segurança necessária para que sua criação não fique sem proteção caso adentre no domínio público. Conforme Bittar (1992, p.08):

"[...] direito do autor ou direitos autorais "são direitos de cunho intelectual, que realizam a defesa dos vínculos, tanto pessoais, quanto patrimoniais do autor, com sua obra, de índole própria, ou sui generis, a justificar a regência específica que recebem nos ordenamentos jurídicos do mundo atual."

Nesse sentido, vale ressaltar que o termo, direito do autor ou direitos autorais era pouco utilizado no período em que a imprensa ainda não existia, pois, as obras intelectuais nesta época eram regidas pelo direito de propriedade. Podemos dizer que este modo de proteção ao direito de autor era justificado, uma vez que, as obras não eram reproduzidas em grandes escalas, pois, os autores não eram dependentes deste tipo de produção. Para Otávio Afonso (2008):

O autor de uma obra (manuscritos, escultura ou pintura) transformava-se em proprietário de um objeto material e podia vende-lo a outra pessoa. Durante a idade média, a reprodução de uma obra era extremamente difícil. Os manuscritos somente podiam ser reproduzidos à mão, o que limitava drasticamente o número de cópias que podiam ser feitas. Por conseguinte, a utilização futura de uma obra não prejudicava os direitos patrimoniais de autor, já que estes não dependiam da produção e reprodução da obra em grandes quantidades

Entretanto, existem estudos que apontam que em Roma o plágio era condenado, pois os autores daquela época dedicavam uma importante atenção a suas obras (peças e/ou manuscritos), pois muitos os tinham como sua fonte de sustento. Assim, surge o que se denomina de plagiator, ou seja, aquele indivíduo que fazia uso da obra intelectual de outrem para obter vantagem econômica, sem a devida autorização formal.

Contudo, com a introdução da imprensa na Europa preconizado por Gutemberg, no século XV, impulsionou a comunicação escrita ao copiar com eficiência e eficácia os exemplares. Por isso, o advento da imprensa é considerado até hoje, como responsáveis pela consolidação da ideia de Direito de Autor.

A Grécia que é considerada um dos berços da cultura ocidental, também não apreciou os direitos de autor da forma que são previstos atualmente mesmo apresentando significativas manifestações criativas na literatura, no teatro, nas artes plásticas e no próprio Direito. Assim como em Roma, o plágio era repudiado, entretanto, existia a possibilidade de se vender a titularidade da obra por inteiro, incluindo-se aí o direito moral do autor. 
O panorama histórico impulsionou significativamente a concretização e avanço dos direitos autorais como por exemplo, o primeiro grupo sistemático de comerciantes de obras intelectuais, que gestaram as primeiras ideias de proteção dos trabalhos impressos, o movimento iluminista e a revolução francesa, que elaboraram os conceitos dessa proteção e as estendeu as obras musicais. Ainda neste período foi aprovado um decreto sobre direito de autor em 1791, que sancionou o direito de execução e representação, e outro de 1793 que garantiu ao autor o direito de forma exclusiva de reprodução. De acordo com Abrão (2007, p. 31):

Nesse avançar histórico, em 1886 , em Berna - Suíça, ocorreu uma reunião gerida
pelos países europeus, a fim de regularem a matéria de direitos autorais de uma
forma mínima, de forma geral e internacional, visando a proteção de obras
cientificas, artísticas e literárias e seus respectivos autores. Nascia a primeira
Convenção Internacional sobre direitos autorais, a semente de todas as legislações
nacionais posteriores.

A primeira lei que afiançava a proteção do direito individual sobre uma obra impressa surgiu na Inglaterra em 10 de abril de 1710, conhecida como lei da Rainha Ana ou Copyright Act, ou seja, Ato do Direito de Cópia. Vale ressaltar que esta lei tinha a finalidade de proteger os editores contra a reprodução ilegal e sem autorização de seus impressos, porém ainda não havia real proteção dos autores das produções intelectuais e sim, apenas o privilégio de impressão. Abrão (2007, p.33) diz:

A quase totalidade dos países do mundo aderiu aos dois instrumentos. Dessa
simbiose, e da vocação cada vez mais internacionalizada dos direitos de autor,
surgiram as mais díspares definições e entendimentos acerca de um e de outro
instituto, o sistema do copyright e o dos direitos de autor. A uma, porque é inegável
a influência da indústria estadunidense na produção e difusão das suas obras, e das
que elege nos países onde tem filiais. A duas, porque a informação jornalística sobre
esses mesmos sistemas, também originada de gerências internacionais, caminham
numa velocidade muito maior que a da própria informação legislativa nacional. O
resultado é que os conceitos, muitas vezes, se confundem, a ponto de divulgar como
cogentes, informações de conteúdo puramente mercadológico, desconhecidos do
sistema e da hierarquia legislativa interna.

Percebe-se que são inúmeras as orientações históricas que elucidam as origens das concepções de modo a abranger obras semelhantes e diferentes. É importante enfatizar que países como a Dinamarca e os Estados Unidos criaram e divulgaram a sua própria legislação, contudo, no final do século XIX, vários Estados também haviam publicado oficialmente as suas leis sobre direito de autor, e inclusive, assinaram o primeiro acordo multilateral sobre o assunto: a Convenção de Berna de 1886 que é considerada um ponto 
de referência do Direito Autoral, do qual o Brasil é subscritor desde 1922. Sobre a convenção de Berna, Branco \& Paranaguá (2009, p. 17) versam:

\begin{abstract}
A convenção impôs verdadeiras normas de direito material, além de instituir normas reguladoras de conflitos. Mas o que de fato impressiona é que, apesar das constantes adaptações que sofrem em razão de seu texto [...], a Convenção de Berna, passados mais de 120 anos de sua elaboração, continua a servir de matriz para a confecção das leis nacionais (entre as quais a brasileira) que irão, no âmbito de seus Estados signatários, regular a matéria atinente aos direitos autorais. Inclusive no que diz respeito a obras disponíveis na internet.
\end{abstract}

Assim, além da convenção de Berna, havia outros documentos internacionais que versavam sobre o direito de autor a exemplo da Convenção Universal e da convenção de Roma que regularizava os direitos conexos do autor em 1961. Conforme Lopez (1993, p. 100):

Perante o desenvolvimento das relações internacionais e dos meios de produção, reprodução e tradução das obras a outros idiomas, a proteção nacional mostrou-se insuficiente, gerando a necessidade de proteger também as obras de autores estrangeiros, até então destituídas de proteção prevista pelas legislações internas da maioria dos países.

Desse modo a Convenção de Berna torna possível a padronização da proteção internacional dos direitos de autor. A convenção Universal aconteceu em Genebra, em 1952 e ficou conhecida como Convenção Universal sobre Direitos de Autor, tinha como principal objetivo integrar as duas correntes, os "direitos de autor" (francesa) e a do copyright (anglosaxã). Desse modo, os direitos autorais, mesmo ainda relacionados aos direitos de edição, apresentaram um valioso avanço no que concerne à sua regulamentação, estabelecendo um equilíbrio entre os privilégios dos autores e dos editores.

Assim considera-se a Convenção de Berna relevante para o desenvolvimento dos direitos referentes ao autor, com a aceitação na Constituição de diversos países, beneficiando a extensão cultural e o acesso ao conhecimento intelectual, artístico e científico inclusive no Brasil.

No que pese essa proteção histórica que foi dada aos Direitos Autorais, cotidianamente a sociedade se vê afrontada por litígios e problemas ligados ao uso massificado da informática. Nesse diapasão, um dos grandes desafios para o Direito é a compreensão e o acompanhamento das inovações geradas pela tecnologia, garantindo a pacificação social.

Segundo CORRÊA, (2000, p. 3), “A tecnologia digital é uma realidade, e justamente por isso estamos diante da criação de lacunas objetivas, as quais o Direito tem o dever de estudar, entender e, se necessário, preencher." Resta patente que as pessoas que não se 
adaptarem a esta nova ferramenta estarão, de certa forma, excluídas da sociedade globalizada. Por fim, o Direito deve observar este eminente campo.

\title{
O MUNDO VIRTUAL É TERRA SEM LEI?
}

As mudanças surgidas no século XXI, mostra que a globalização trouxe expressões como, "sociedade de informação"; "sociedade digital" ou até mesmo, "sociedade do conhecimento", que, por sua vez, estabelece ligação a qualquer meio tecnológico, processo de comunicação, e essencialmente à internet.

Inegavelmente com o advento da rede mundial de computadores a comunicação consegue romper as fronteiras dos estados e a informação consegue de forma instantânea chegar em qualquer lugar no mundo. Nesse interim, devemos lembrar que a comunicação sempre foi uma das grandes precursoras da evolução do homo sapiens. O que antes acontecia através de gestos e expressões corporais, a partir dessa evolução, chegamos à criação da palavra. Surgindo assim, as imagens, os símbolos, a música, os escritos em geral. Para Althusser (1965, p.43):

Ao muito pouco conhecido entre nós (mas imprescindível) filósofo marxista TranDuc-Thao, devemos a mais avançada reconstituição hipotética da evolução dos antropoides aos pré-hominídeos e destes ao homo habilis, através notadamente da sinergia entre mão e cérebro, trabalho e comunicação verbal.

Desse modo, a comunicação foi o fator essencial para a evolução e desenvolvimento de tarefas que promoveram melhorias das atividades primitivas. Acompanhando essa evolução, a rede de computadores é hoje um dos mais modernos meios de comunicação, repercutindo em todo o mundo como uma notória tecnologia de informação. Tal fenômeno se deve a rapidez, agilidade e facilidade condições em que o indivíduo pode interagir, com toda comodidade que a rede oferece.

De acordo com Mattelart (2002):

\begin{abstract}
Inúmeras são as terminologias ao longo do tempo para definir a sociedade. traça um percurso histórico no qual representa o avanço da sociedade. Em linhas gerais podemos representá-la como, num primeiro momento, a sociedade inspirada pela mística do número, cujo foco era os métodos matemáticos; no segundo, a sociedade como indústria com o poder da técnica e; no terceiro a sociedade das redes, buscando a universalização até à sociedade da informação com o paradigma das tecnologias de informação e comunicação.
\end{abstract}

A expansão da internet deu-se na década de 90 por meio dos navegadores que facilitavam a comunicação, surgindo então, os provedores de acesso e portais de serviços 
online que colaboraram para esse avanço passando a ser usada por vários segmentos sociais como salas de chat, desempregados a procura de empregos, as empresas para uma melhor negociação e obtenção de lucros através das vendas online, portais de músicas.

Para Levy (1999), a Internet foi importante no intuito de facilitar a comunicação através de correio eletrônico, fóruns, chats, blogs, comunidades virtuais, dentre outras que integram o ciberespaço. Nesse mesmo interim, Castells, (2002), estabelece a importância das redes sociais como um ponto crucial de transformação da comunicação em nossa sociedade, isso fica clarividente a partir de 2006, quando a internet impulsionou o progresso das redes sociais como o Orkut, logo após Facebook, Twitter, Google Plus e Instagram e o WhatsApp.

A internet forma hoje a maior rede de comunicação em massa que apresenta todos os conteúdos e serviços que liga entre si todos os usuários do globo terrestre promovendo o compartilhamento das informações, conteúdos obras artísticas etc. Para Paesini (2000, p. 106): “A internet é um sistema de comunicação interligado que, diversamente da mídia de massa tradicional, tem na base, e como fundamento, a participação do usuário na criação e na fruição dos conteúdos e dos serviços."

A internet tornou-se um componente essencial para a era moderna que por meio do sistema, oportuniza a evolução das informações através da globalização. Assim, na atualidade a internet interliga milhões de computadores no mundo inteiro, admitindo a troca e compartilhamento de informações, cultura e conhecimento somente por um clique de distância.

O fato é que a Internet é uma realidade que cresce assustadoramente e a cada dia mais pessoas a utilizam para realizar pesquisas, se comunicar, adquirir bens, celebrar contratos, fazer negócios e divulgar obras protegidas por Direitos Autorais. A era virtual nasce meio a uma geração que busca cada vez mais mostrar o que faz no dia a dia ou o que produz em uma espécie de sociedade do espetáculo, nesse sentido, faz-se necessário unir os aspectos tecnológicos da Internet com os jurídicos para proteger esses valores extremamente relevantes.

Entretanto, vigorou na doutrina brasileira a ideia de que a Internet não poderia ser regulada, dado o seu caráter internacional e a falta de adequação e eficácia dos mecanismos tradicionais de regulamentação em face das peculiaridades da rede. Pensamento esse que teve 
origem na doutrina jurídica norte-americana principalmente no manifesto da independência do ciberespaço ${ }^{4}$.

Além da ideia da impossibilidade de regulamentação da Internet haver persistido por muito tempo, existe outra a doutrina que parte do entendimento de que a Internet não precisa ser regulada.

No Brasil, essa corrente de pensamento de que a Internet não podia ser regulamentada contribuiu para um atraso significativo na percepção de que a tecnologia digital conjugada com a internet demanda uma intervenção normativa imediata, para composição dos interesses de usuários, detentores da propriedade intelectual e provedores de serviços e infraestrutura. Essa intervenção normativa faz-se necessária principalmente como forma de estabelecer com clareza a distribuição de responsabilidade e riscos inerentes à Internet [...] (LEMOS, 2005, p. 95, grifo do autor).

No que pese existir uma corrente que defenda que a Internet deve ser um meio livre, atualmente nos deparamos com os crescentes avanços dessas tecnologias e meios de comunicação em massa, que indicam impacto direto com a disciplina do direito autoral.

Diante desse novo cenário, precisamos discutir a proteção das obras intelectuais que se encontram na internet, sejam elas disponibilizadas pelo próprio autor ou por terceiros com ou sem o seu consentimento. Principalmente, precisamos debater se o conceito de obras utilizadas para uso privado continua inalterado por conta da capilaridade da internet, questão é que a evolução tecnológica alterou o direito autoral causando sérios problemas. De acordo com Santos (2001, p. 138):

Alguns sustentam que os avanços tecnológicos representados pelos novos meios de comunicação de massa (como o cinema e a radiodifusão) foram responsáveis pelas maiores transformações no Direito Autoral, por terem revolucionado pela primeira vez o processo de criação intelectual e por terem gerado novas formas de proteção.

As características do ambiente digital podem acarretar a implosão do regime de proteção autoral com uma nova revolução do processo criativo e da forma de utilização da obra intelectual. (SANTOS 2005, P. 139).

Dessa maneira o direito autoral não protegeria apenas o direito de reprodução da obra intelectual, assim como, o direito de usá-la de modo exclusivo. O fato é que a sociedade da informação gerou mudanças enormes no Direito Autoral.

O Direito Autoral Tradicional, surgido na era gutenbergueana, já havia passado anteriormente ao surgimento do mundo digital por diversas transformações, da mesma forma

\footnotetext{
${ }^{4}$ Nos primeiros tempos da Internet, havia um sentimento de que ela nos dava a liberdade de fazer as coisas independentemente dos governos e da legislação do país. De fato, em fevereiro de 1996, John Perry Barlow, um ativista de Internet, publicou a 'Declaração de Independência do Ciberespaço', na qual instava os governos a manterem-se afastados da rede, declarando: 'O espaço cibernético não se limita a suas fronteiras.
} 
como a obra intelectual, fruto da criação humana, já havia deixado de apresentar a mesma configuração do que poderíamos chamar de fase romântica da criação, ou seja, a obra como a manifestação da personalidade de seu criador. (SANTOS 2001, p. 139):

Entretanto Lei 9.610/98, que protege os direitos autorais engloba toda e qualquer obra, inclusive obras intelectuais dispostas no mundo digital. Involuntariamente as evoluções que têm acontecido no século XXI, não invalida a necessidade de proteção. Assim, a interpretação da lei deve acontecer de modo simultâneo para que os delitos também alcançam às obras que se encontram no "domínio público que é a internet."

\section{CONSIDERAÇÕES}

Sabe-se que atualmente, a internet e as redes sociais estão cada vez mais presentes em nossa vida e, por sua vez, se tornaram ferramentas indispensáveis para nós e para as empresas que investem na comunicação. Portanto, é imprescindível que tenhamos o conhecimento de como devemos ministrar esse arcabouço de informações fornecidas pela internet, pois nem tudo que se encontra nela é necessariamente de uso liberado para toda ou qualquer finalidade, ou seja, esse grandioso arquivo de conteúdos não é de domínio público.

As informações contidas na internet dependem de autorização prévia de seus autores para utilização. A violação dos direitos autorais praticados através da rede está sujeita às normas já vigentes em nosso país como na Constituição Federal de 1988, o Código Civil, o Código de Defesa do Consumidor, Direito autoral e o Código Penal. O crime de violação pode ser entendido como, "violar direitos de autor e os que lhe são conexos" (CP, art.184).

A Constituição não se preocupou com uma proteção que atendesse especialmente a paternidade da obra e sim o abrigo do direito de propriedade em seus aspectos sociais e solidário, contemplando as teorias das gerações dos direitos fundamentais com a proteção constitucional do direito de autor. Desta forma, a constituição assegura "aos autores o direito exclusivo de utilização, publicação ou reprodução de suas obras, e até mesmo a transferência destas aos seus herdeiros pelo tempo que a lei fixar" (CF, Art.5, XXVII).

Isso posto, evidencia que os direitos autorais estão inseridos na segunda e terceira geração de direitos, tencionando seus aspectos quanto a direito econômico, social e cultural, e quanto ao princípio da solidariedade. Porém, o constituinte brasileiro atribuiu tal noção preferencialmente aos direitos de propriedade, em contenção ao direito do autor. 
Para manter uma postura ética no uso dos conteúdos da internet é essencial atender o que está previsto na Lei de Direitos Autorais para não praticar a violação deles, pois o homem precisa cumprir na sociedade o seu papel jurídico, enquanto sujeito de direitos e obrigações. Sua personalidade é instituída a partir de normas que impõe limites aos direitos constituídos.

A liberdade de informação é um direito que o homem tem por lei, assim além dele ser informado ele também informa, ou seja, a informação ultrapassa por dois aspectos o ativo que possibilita expressar as ideias e o passivo quando absorve a informação das outras pessoas. Entretanto, a violação dos direitos autorais configura- se crime formal sendo consumado independente do ser naturalístico.

\section{REFERÊNCIAS}

ABRÃO, Eliane Yachouh. Considerações em torno do Direito Autoral no Mundo Digital, In: VALLE, Regina Ribeiro do (org.), E-dicas: O Direito na Sociedade da Informação, São Paulo: Usina do Livro, 2007.

. Direitos Autorais e Direitos Conexos, São Paulo: Editora do Brasil S.A., 2002. AFONSO, Otavio. Direito Autoral: conceitos essenciais, São Paulo: Manole, 2008.

ALTHUSSER, Louis. Marxisme et humanisme, in Pour Marx, Paris: Maspero, 1965. BARROS, Carla Eugenia Caldas. Manual de Direito da Propriedade Intelectual, Aracaju: Evocati, 2007.

BOAVENTURA, Edivaldo Machado. Metodologia da pesquisa: monografia, dissertação, tese, São Paulo: Atlas, 2004.

BRANCO, Sérgio; PARANAGUÁ, Pedro. Direitos Autorais, Rio de Janeiro: Editora FGV, 2009.

BRASIL. Lei no 9.610, de 19 de fevereiro de 1998. Lei sobre Direitos Autorais. Disponível em http://www.planalto.gov. br/ccivil/leis/19610.htm. Acesso em 15.07.2012.

. Lei no 10.406, de 10 de janeiro de 2002. Código Civil. Disponível em http://www.planalto.gov.br/ccivil_03/LEIS/2002/L10406.htm. Acesso em 15.07.2016.

Decreto nº 2848/1940. Define o Código Penal Brasileiro, 5ª, ed. São Paulo: Saraiva, 2009.

CONVENÇÃO DE BERNA. Decreto $n^{\circ} 75.699$, de 06.05.75. Convenção de Berna para a Proteção das Obras Literárias e Artísticas, de 9 de setembro de 1886, Revista em Paris, a 24 de julho de 1971. Disponível em: http://www.cultura.gov.br/site/wpcontent/uploads/2007/10/decreto-75699.pdf Acesso em 15.05.2021. 
CARVALHEIRO, J. dos S. A concepção de autor em Bakhtin, Barthes e Foucault.

Signum: Estudos de Linguagem, Volume 11, número 2. Londrina: Universidade Estadual de Londrina, 2008.

CORRÊA, Gustavo Testa. Aspectos jurídicos da Internet. São Paulo: Saraiva, 2000.

FRAGOSO, João Henrique da Rocha. Direito Autoral: Da antiguidade à Internet, São Paulo: Quartier Latin, 2009.

LOPEZ, Marisela Gonzalez. El derecho moral de autor en la ley española de propiedad intelectual, Madrid: Marcial Pons, 1993.

BITTAR, Carlos Alberto. Direito de autor, Rio de Janeiro: Forense Universitária, 1992.

CASTELLS, Manuel. A Sociedade em Rede, São Paulo: Editora Paz e Terra, 1999.

CASTRO, de Álvaro. Propaganda e Mídia Digital: A Web como a Grande Mídia do Presente, Rio de Janeiro: Qualitymark, 2000.

GANDELMAN, Henrique. De Gutemberg à Internet, Direito autoral na era digital, $2^{\mathrm{a}}$., ed., Rio de Janeiro: Record, 2007.

LAFER, Celso. A Reconstrução dos Direitos Humanos - Um diálogo com o pensamento de Hannan Arendt, São Paulo: Companhia das Letras, 1991.

LEMOS, Ronaldo. Direito, tecnologia e cultura. Rio de Janeiro: Fgv, 2005.

LÉVY, Pierre. Cibercultura, São Paulo: Editora 34, 1999.

MANSO, Eduardo J. Vieira. O que é Direito Autoral, 2a . ed., São Paulo: Brasiliense, 1992.

MATTELART, A. 2002. História da sociedade da informação, São Paulo: Loyola, 2002.

MORAES, Walter. Artistas, intérpretes e executantes. São Paulo: Revista dos Tribunais, 2003.

NASSAR, Paulo; FIGUEIREDO, Rubens. O que é Comunicação Empresarial - Coleção

Primeiros Passos, São Paulo: Brasiliense, 1995.

NIGRI, Deborah Fisch. Direito Autoral e a Convergência de Mídias - Cadernos de Direito da Internet, vol., II., Rio de Janeiro: Editora Lumen Juris, 2006.

SANTOS, Manoel J. Pereira dos. O direito autoral na internet, In: GRECO, Marco Aurelio; MARTINS, Ives Gandra da Silva (Coords.). Direito e internet: relações jurídicas na sociedade informatizada, São Paulo: Revista dos Tribunais, 2001. 
SANTOS, N. B. A historiografia brasileira das Relações Internacionais desde 1990: Relações Internacionais e Política Externa Brasileira, XXIII Simpósio Nacional de História, Londrina, 2005.

PAESANI, Liliana Minardi. Direito e Internet: Liberdade de Informação Privacidade, $4^{\mathrm{a}}$., ed., São Paulo: Atlas, 2008.

STOLCO, Rui. Tratado de responsabilidade civil: doutrina e jurisprudência, $7^{\mathrm{a}}$ ed., revista, atualizada e ampliada, São Paulo: Revista dos Tribunais, 2007. 